\title{
Letter to the editor re: citations for the literature on spontaneous spinal epidural hematoma by Babayev et al. (2016)
}

\author{
Paul Steinbok ${ }^{1}$
}

Received: 30 March 2016/Accepted: 5 April 2016 / Published online: 25 April 2016

(C) Springer-Verlag Berlin Heidelberg 2016

\section{Dear Editor:}

I read with interest the case report and review of the literature on spontaneous spinal epidural hematoma by Babayev et al. [1]. I was surprised that in what appeared to be an exhaustive review of prior cases reported in the literature going back to 1832, the case reported by Vitali and Steinbok in 2008 [2] was missing. I thought that perhaps this was missed in the literature search because the title, content or key words were such that it would have been missed. I went to pubmed and entered "spontaneous spinal epidural hematoma" and the citation came up. Thus, it is not clear why this would have been missed and I have to wonder how complete is the review done by these authors.

Unfortunately, incomplete or inaccurate citations are not unusual occurrences. One might ignore it and argue that the omission in this case and in many others changes nothing in the conclusion of the article. However, I wish to make the point that accurate and complete appropriate citations are part of being ethical in scientific publications. In 1995, I published an article titled "Ethical considerations relating to writing a medical scientific paper for publication" [3] and in that article, under the section titled "Citing other work", I made the following comments, which are still relevant and bear repetition: "The purpose of citations in scientific publications should be: (1) to give credit to previous workers in the field where credit

Paul Steinbok

psteinbok@cw.bc.ca

1 Division of Neurosurgery, BC Children's Hospital and University of British Columbia, 4480 Oak St., Room K3-159, Vancouver, BC V6h 3V4, Canada is due, (2) to relate the work of others to the scientific work that is being reported, and (3) to provide direction to the readers regarding literature relevant to the scientific work being published. It is dishonest not to give credit where credit is due, and one must be honest in citing the work of others. It is unethical to omit citing important original work, and to bias citations towards prior publications of colleagues or friends. Citations must be accurate with respect to the content of the cited publications. Too often authors do not read the original article and perpetuate errors made by previous authors who have cited the same article, and this is intrinsically dishonest, since the citation implies to the reader that the author has actually read the cited work." [3].

In this day and age, when electronic searches are so easy to do, there is a little excuse for deficiencies in citing other work. One might argue that the reviewers or editors should pick up these errors, but I think the onus has to be on the authors to cite accurately and fully.

\section{Compliance with ethical standards}

Conflict of interest The author has no conflict of interest.

\section{References}

1. Babayev R, Eksi MS (2016) Spontaneous thoracic epidural hematoma: a case report and literature review. Childs Nerv Syst 32:181-187. doi:10.1007/s00381-015-2768-5

2. Vitali AM, Steinbok P (2008) Spontaneous spinal epidural hematoma following weight lifting. Can J Neurol Sci 35:262-264

3. Steinbok P (1995) Ethical considerations relating to writing a medical scientific paper for publication. Childs Nerv Syst 11:323-328 